\title{
Human Immunodeficiency Virus Infection of Human Astrocytes Disrupts Blood-Brain Barrier Integrity by a Gap Junction-Dependent Mechanism
}

\author{
Eliseo A. Eugenin, ${ }^{1}$ Janice E. Clements, ${ }^{3}$ M. Christine Zink, ${ }^{3}$ and Joan W. Berman ${ }^{1,2}$ \\ Departments of ${ }^{1}$ Pathology and ${ }^{2}$ Microbiology and Immunology, Albert Einstein College of Medicine, Bronx, New York 10461, and ${ }^{3}$ Department of \\ Molecular and Comparative Pathobiology, The Johns Hopkins University School of Medicine, Baltimore, Maryland 21205
}

HIV infection of the CNS is an early event after primary infection, resulting in neurological complications in a significant number of individuals despite antiretroviral therapy (ART). The main cells infected with HIV within the CNS are macrophages/microglia and a small fraction of astrocytes. The role of these few infected astrocytes in the pathogenesis of neuroAIDS has not been examined extensively. Here, we demonstrate that few HIV-infected astrocytes ( $4.7 \pm 2.8 \%$ in vitro and $8.2 \pm 3.9 \%$ in vivo) compromise blood- brain barrier (BBB) integrity. This BBB disruption is due to endothelial apoptosis, misguided astrocyte end feet, and dysregulation of lipoxygenase/cyclooxygenase, $\mathrm{BK}_{\mathrm{Ca}}$ channels, and ATP receptor activation within astrocytes. All of these alterations in BBB integrity induced by a few HIV-infected astrocytes were gap junction dependent, as blocking these channels protected the BBB from HIV-infected astrocytemediated compromise. We also demonstrated apoptosis in vivo of BBB cells in contact with infected astrocytes using brain tissue sections from simian immunodeficiency virus-infected macaques as a model of neuroAIDS, suggesting an important role for these few infected astrocytes in the CNS damage seen with HIV infection. Our findings describe a novel mechanism of bystander BBB toxicity mediated by low numbers of HIV-infected astrocytes and amplified by gap junctions. This mechanism of toxicity contributes to understanding how CNS damage is spread even in the current ART era and how minimal or controlled HIV infection still results in cognitive impairment in a large population of infected individuals.

\section{Introduction}

Human immunodeficiency virus type 1 (HIV) invades the CNS early after primary infection and causes HIV-associated neurological disorders in $40-60 \%$ of infected individuals even in the current antiretroviral therapy era (Anthony et al., 2005). In vivo, microglial cells and perivascular macrophages are the predominant cell types productively infected by HIV (Wiley et al., 1986; Cosenza et al., 2002). However, a small population of HIVinfected astrocytes has been detected using diverse techniques both in vivo and in vitro (Wiley et al., 1986; Conant et al., 1994; Nuovo et al., 1994; Tornatore et al., 1994b; Bagasra et al., 1996; Takahashi et al., 1996; Ohagen et al., 1999; Eugenin and Berman, 2007; Churchill et al., 2009). The importance of these few infected astrocytes in the pathogenesis of neuroAIDS has not been examined extensively. Our group demonstrated that, although only

\footnotetext{
Received March 22, 2011; revised April 14, 2011; accepted April 15, 2011.

Author contributions: E.A.E. and J.W.B. designed research; E.A.E. and J.W.B. performed research; J.E.C. and M.C.Z. contributed unpublished reagents/analytic tools; E.A.E., J.E.C., M.C.Z., and J.W.B. analyzed data; E.A.E. and J.W.B. wrote the paper.

This work was supported by National Institute of Mental Health (NIMH) K01 Grant MH076679 (E.A.E.), National Institutes of Health (NIH) Grants R01 NS055648 and P01 MH070306 (J.E.C.), NIH Grants R01 MH069116 and R01 NS44815 (M.C.Z.), and NIMH Grants MH075679 and MH083497 (J.W.B.). We thank the NIH Centers for AIDS Research (CFAR) Grant Al-051519 and a pilot project from CFAR at Albert Einstein College of Medicine.

Correspondence should be addressed to Dr. Eliseo A. Eugenin, Department of Pathology, F727, Albert Einstein College of Medicine, 1300 Morris Park Avenue, Bronx, NY 10461. E-mail: eliseo.eeugenin@einstein.yu.edu.

DOI:10.1523/JNEUROSCI.1460-11.2011

Copyright $\odot 2011$ the authors $\quad 0270-6474 / 11 / 319456-10 \$ 15.00 / 0$
}

few astrocytes become infected in vitro $(4.7 \pm 2.8 \%$ of the total astrocytes in the culture) and HIV production is extremely low or undetectable, gap junction (GJ) channels amplify and spread toxic signals to uninfected cells in culture (Eugenin and Berman, 2007). We now demonstrate that these few HIV-infected astrocytes, with no detectable viral production, cause dramatic alterations in blood-brain barrier (BBB) physiology in vitro. We detected similar toxic effects on the BBB in vivo, using brain tissue sections obtained from simian immunodeficiency virus (SIV)infected macaques.

The BBB is composed of highly specialized microvascular endothelial cells on top of an extracellular matrix, the basal lamina. Astrocyte end feet contact the basal lamina and are close to the endothelial cells as well as accessory cells including pericytes, perivascular macrophages, and microglia (Abbott, 2002; Ballabh et al., 2004). Astrocytes and their end feet processes surround the brain capillaries, providing factors important in the development and maintenance of the BBB (Goldstein, 1988; Risau and Wolburg, 1990; Risau, 1991; Hayashi et al., 1997). Astrocytes and their end feet regulate BBB physiology by soluble factors (Rubin and Staddon, 1999; Hawkins and Davis, 2005; Iadecola and Nedergaard, 2007), and by direct intercellular communication through GJ channels, and perhaps by connexin/pannexin hemichannels on the surface of the cells that connect the cytoplasm and the extracellular environment. GJs are conglomerates of channels that enable the exchange of small molecules up to 1.2 $\mathrm{kDa}$ between the cytoplasm of adjacent cells (Saez et al., 2003). 
Each channel is formed by the docking of two hemichannels, located in apposing cell membranes, and each hemichannel is an assembly of six connexins (Cxs). In pathological conditions including inflammation and viral infections, GJ communication is reduced (Danave et al., 1994; Faccini et al., 1996; Rouach et al., 2002; Kielian and Esen, 2004; Knabb et al., 2007). However, HIV infection of astrocytes maintains expression of $\mathrm{Cx} 43$ and functional GJ communication allowing the spread of toxic signals generated from the few infected astrocytes to neighboring uninfected astrocytes (Eugenin and Berman, 2007). We now demonstrate that these few infected astrocytes have profound effects, through a GJ-dependent mechanism, on BBB integrity by dysregulating endothelial survival, the stability of astrocyte end feet, and their signaling.

\section{Materials and Methods}

Materials. DMEM, FBS, and trypsin-EDTA were from Invitrogen. Antibodies to glial fibrillary acidic protein (GFAP), von Willebrand factor (vWF), and Cy3- or FITC-conjugated anti-rabbit IgG and Cy3 or FITC anti-mouse IgG antibodies were from Sigma-Aldrich. Purified mouse $\operatorname{IgG}_{2 \mathrm{~B}}$ and $\operatorname{IgG}_{1}$ myeloma proteins were from Cappel Pharmaceuticals, and nonimmune sera was from Santa Cruz Biotechnology. HIV-p24 monoclonal antibody was from Abcam. SIVmac251-gp41 (KK41) antibody was from the NIH repository (Bethesda, MD). In situ cell death detection kit [terminal deoxynucleotidyl transferase-mediated biotinylated UTP nick end labeling (TUNEL)] was from Roche. Arachidonic acid (AA) $(10 \mu \mathrm{M})$, Tocrisolve 100 (to dissolve AA), baicalein $(5 \mu \mathrm{M})$, paxilline $(1 \mu \mathrm{M})$, indomethacin $(10 \mu \mathrm{M})$, and ATP $(1 \mu \mathrm{M})$ were from Tocris Bioscience.

Human astrocyte cultures. Cortical human fetal tissue was obtained as part of an ongoing research protocol approved by the Albert Einstein College of Medicine. The preparation of astrocyte cultures was performed as previously described (Eugenin and Berman, 2003, 2007; Eugenin et al., 2003).

Human brain microvascular endothelial cells. Primary human brain microvascular endothelial cells (BMVECs) (Applied Cell Biology Research Institute, Kirkland, WA) were grown in M199 media supplemented with $20 \%$ heat-inactivated newborn calf serum (Invitrogen), $5 \%$ heat-inactivated human serum type $\mathrm{AB}$ (Lonza), 1\% penicillin-streptomycin (Invitrogen), 0.8\% L-glutamine (Invitrogen), 0.1\% heparin (Sigma-Aldrich), 0.1\% ascorbic acid (Sigma-Aldrich), 0.25\% endothelial cell growth supplement (Sigma-Aldrich), and $0.06 \%$ bovine brain extract (Clonetics).

HIV infection of primary cultures of astrocytes. Confluent cultures of human astrocytes (passages 2 and 3) were infected by incubation with $\mathrm{HIV}_{\mathrm{ADA}}(20-50 \mathrm{ng} / \mathrm{ml} \mathrm{HIV}-\mathrm{p} 24)$, using a previously described protocol (Ohagen et al., 1999; Eugenin and Berman, 2007). Briefly, astrocyte cultures were exposed to virus for $24 \mathrm{~h}$, medium was removed, and astrocytes were washed extensively to eliminate the unbound virus before addition of fresh medium. Immunofluorescence analyses for GFAP (an astrocyte marker), CD68 or isolectin-B4 (a microglia/macrophage marker), and HIV-p24 were used to identify the presence of virus in GFAP-positive cells and to demonstrate no contamination with CD68positive microglia.

BBB model. This in vitro BBB model consists of primary human BMVECs and primary astrocytes (uninfected or HIV infected for $3 \mathrm{~d}$ ) in coculture on opposite sides of a gelatin-coated, $3 \mu \mathrm{m}$ pore-size tissue culture insert (Falcon; BD Biosciences Discovery Labware) as we previously described (Hurwitz et al., 1993, 1994; Weiss et al., 1998; Eugenin and Berman, 2003, 2007). This model exhibits EC expression of BBB markers. Cocultures were maintained for $3 \mathrm{~d}$ to enable contact between astrocyte end feet with BMVECs on the opposite side of the model as described previously (Eugenin and Berman, 2003).

Immunofluorescence and apoptosis assays. Tissue sections, BBB inserts, and primary cultures of human astrocytes were fixed and permeabilized in $70 \%$ ethanol for $20 \mathrm{~min}$ at $-20^{\circ} \mathrm{C}$. Tissue sections and BBB cocultures, endothelial cells, and astrocytes, the top or bottom of the inserts, respec- tively, were incubated in TUNEL reaction mixture at $37^{\circ} \mathrm{C}$ for $1 \mathrm{~h}$, washed three times in PBS, and incubated in blocking solution $(5 \mathrm{~mm}$ EDTA, $1 \%$ fish gelatin, $1 \%$ essentially Ig-free BSA, $2 \%$ human serum, and $2 \%$ horse serum) for $30 \mathrm{~min}$ at room temperature. Tissue sections, BBB inserts, or cells were incubated in the proper diluted primary antibody (anti-vWF or anti-GFAP; 1:100 and 1:600) overnight at $4^{\circ} \mathrm{C}$. Samples were washed several times with PBS at room temperature and incubated with the appropriate secondary antibodies conjugated to FITC or Cy3 for $1 \mathrm{~h}$ at room temperature, followed by another wash in PBS for $1 \mathrm{~h}$. Tissue sections, BBB inserts, or cells were then mounted using antifade reagent with DAPI, and the cells were examined by confocal microscopy. Antibody specificity was confirmed by replacing the primary antibody with a nonspecific myeloma protein of the same isotype or nonimmune serum. The percentage of apoptotic astrocytes or BMVECs was determined by double immunofluorescence staining for TUNEL and GFAP or vWF using confocal microscopy. In the tissue sections and BBB inserts, the total numbers of astrocytes or BMVECs, as well as the number of cells that were TUNEL positive in 10 fields per coverslip or BBB insert were counted, and the data were expressed as percentage apoptotic astrocytes or BMVECs.

SIV infection studies using macaques. Juvenile male pig-tailed macaques (Macaca nemestrina), aged 2-3 years, were inoculated intravenously with SIV/17E-Fr [10,000 tissue culture infectious doses $\left.\left(\mathrm{TCID}_{50}\right)\right]$ and $50 \mathrm{AID}_{50}$ of SIV/DeltaB670. SIV/17E-Fr is a macrophagetropic and neurovirulent recombinant strain derived from SIVmac239 by substituting the entire env and nef genes as well as the $3^{\prime}$ long terminal repeats of SIVmac239 with those from SIV/17E-Br, a virus derived from SIVmac239 by serial passage in rhesus macaques and subsequent isolation from the brain of a macaque with fulminant encephalitis (Flaherty et al., 1997; Mankowski et al., 1997). This SIV-infected macaque model follows an accelerated course: briefly, acute infection peaks $10 \mathrm{~d}$ after inoculation, there is a decrease in viral load in both the plasma $(\sim 1 \log )$ and CSF $(\sim 1-2 \operatorname{logs})$ at $14-18 \mathrm{~d}$ after inoculation, and AIDS develops in all macaques by $84 \mathrm{~d}$ after inoculation when $>90 \%$ of the infected macaques exhibit pulmonary and CNS lesions (Mankowski et al., 1997, 2004; Zink et al., 1999, 2001; Babas et al., 2001). The animals were killed at 4-84 d after inoculation. Before necropsy, animals were perfused with PBS to remove virus-containing blood from the tissues as described previously (Fox et al., 2000). Two to 3 animals per time point $(4,21,56$, and $84 \mathrm{~d}$ after inoculation) were examined, as well as uninfected controls. Regardless of experimental group, macaques were killed once they reached any two of the following five criteria for killing: (1) weight loss of $>15 \%$, (2) $\mathrm{CD} 4{ }^{+}$cell counts $<5 \%$ of baseline level, (3) clinical signs of neurological disease, (4) intractable diarrhea, or (5) opportunistic infection.

Immunofluorescent labeling and analysis of CNS macaque tissue samples. Postmortem macaque brain tissue sections from cortex and cortexwhite matter transition areas were obtained from uninfected controls, and SIV-infected cases at 4, 21, 56, and $84 \mathrm{~d}$ after infection were analyzed by four color immunohistochemical staining for TUNEL (apoptosis staining), DAPI (nuclei staining), SIV-p41 (SIV viral protein), and GFAP (an astrocyte marker). Three sections per CNS region and per time point were examined for each animal. Tissue sections $(10 \mu \mathrm{m})$ were deparaffinized, and antigen retrieval was performed before TUNEL staining. After TUNEL staining and extensive washes, slices were blocked (5 mM EDTA, $1 \%$ fish gelatin, $1 \%$ essentially Ig-free BSA, $2 \%$ human serum, and $2 \%$ horse serum) for $60 \mathrm{~min}$ at room temperature and then incubated with anti-SIV-p41 (SIV viral protein) and GFAP (an astrocyte marker) overnight at $4^{\circ} \mathrm{C}$. The sections were washed with PBS and incubated with secondary antibodies for $1 \mathrm{~h}$ at room temperature, followed by serial washes in PBS for $1 \mathrm{~h}$. Samples were then mounted using Prolong Gold antifade reagent (Invitrogen) and examined by confocal microscopy. Specificity was confirmed by replacing the primary antibody with the appropriate isotype-matched control reagent, anti- $\operatorname{IgG}_{2 \mathrm{~A}}$, or the $\operatorname{IgG}$ fraction of normal rabbit serum (Santa Cruz Biotechnology).

Permeability analysis of BBB model. After $3 \mathrm{~d}$, cocultures of BMVECs with uninfected or HIV-infected cultures of astrocytes were analyzed for BBB integrity using a permeability assay with Evans blue dye coupled to albumin as described previously (Eugenin and Berman, 2003). 

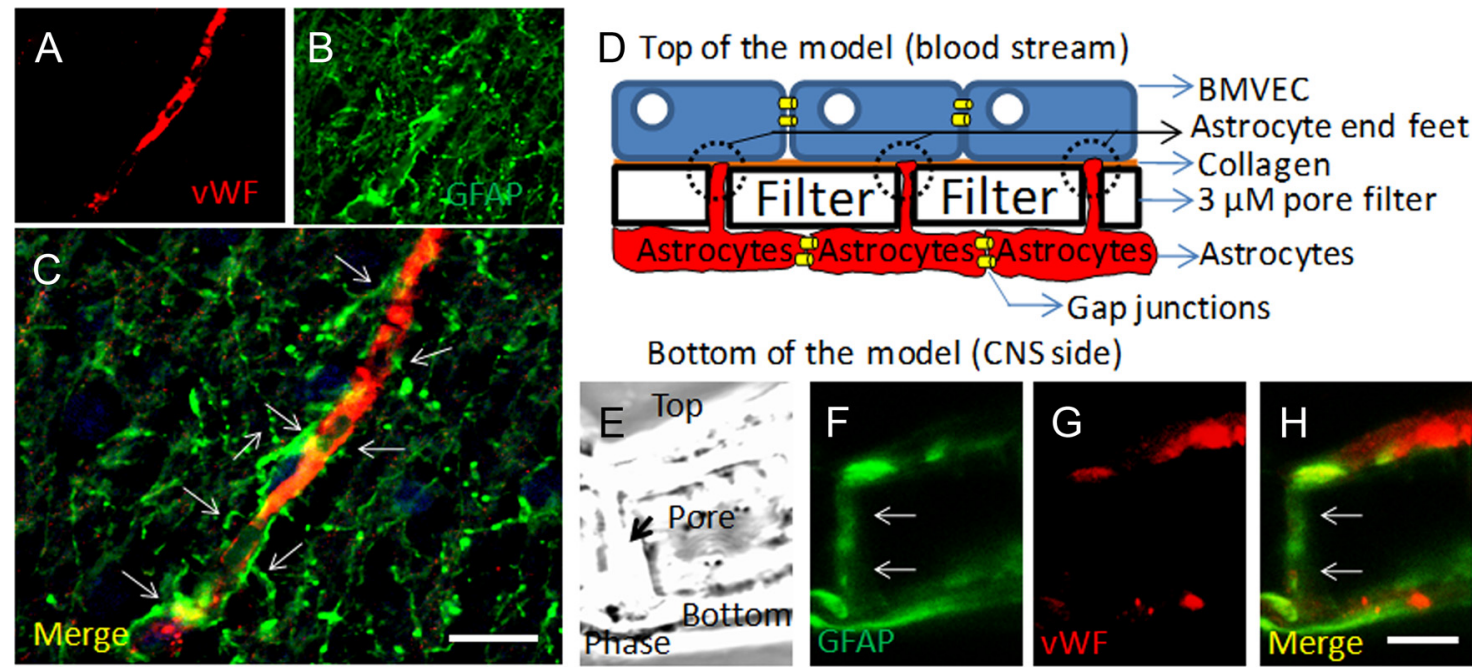

Bottom of the model (CNS side)
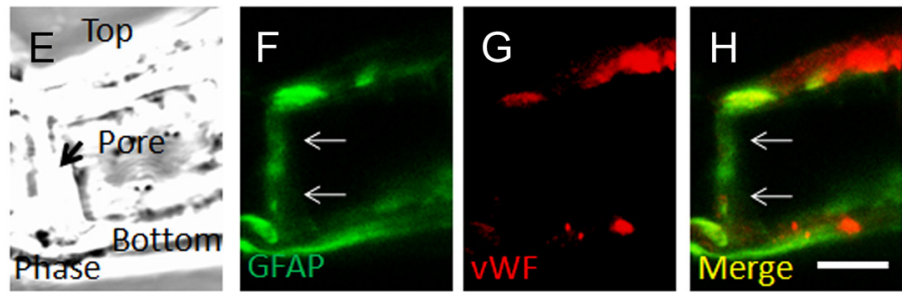

Figure 1. Astrocytes are key cells in the maintenance of the BBB in vivo and in vitro. $A-C$, Staining of human brain tissue sections for vWF (a marker of endothelial cells; red staining) ( $\boldsymbol{A}$ ) and GFAP (a marker of astrocytes; green staining) (B) demonstrates the close interaction between astrocytes and their end feet with endothelial cells in vivo (C) (merge of both colors). $\boldsymbol{D}$, Schematic of our in vitro model of the human BBB, composed of BMVECs grown on denatured collagen on the top of a polycarbonate membrane with $3 \mu \mathrm{m}$ pores, and human astrocytes cultured on the bottom side of the membrane. Astrocytes that are coupled by gap junctions send processes, termed astrocyte end feet, through the $3 \mu \mathrm{m}$ pores. $\boldsymbol{E}-\boldsymbol{H}$, Staining of a cross section of the BBB model (see phase picture; $\boldsymbol{E})$ for GFAP $(\boldsymbol{F})$ or $\operatorname{vWF}(\boldsymbol{G})$ or the merge of both colors demonstrated that vWF staining is in the top of the insert and GFAP-positive astrocytes are on the bottom. Astrocytes send processes from the bottom of the insert to the top of the insert to establish contact with the BMVEC layer. Much of this GFAP staining is also detectable on the top of the insert ( $\boldsymbol{H}$; colocalization of both colors; yellow). Thus, our in vitro model of the human BBB recapitulates many of the astrocyte- endothelial interactions seen in vivo. This model will be used to examine the role of HIV-infected astrocytes in BBB integrity and astrocyte end feet signaling. Scale bar, $50 \mu \mathrm{m}$.

ELISA. HIV-p24 concentrations were determined by ELISA using a kit from PerkinElmer following manufacturer's instructions.

Statistical analysis. Student's one-tailed, paired $t$ test was used. A value of $p<0.05$ was considered significant.

\section{Results}

\section{Astrocytes are an integral part of the structure and function of the $B B B$}

The BBB is a dynamic barrier composed mainly of BMVECs and astrocyte "end feet" in contact with the endothelium to transduce signals from the CNS into the vessels, as well as from the blood into the brain. This helps to regulate adequate blood flow (Rubin and Staddon, 1999; Abbott, 2002; Iadecola and Nedergaard, 2007; Girouard et al., 2010). These close astrocyte-BMVEC interactions can be observed in human brain tissue sections stained for vWF (an endothelial cell marker) (Fig. 1 $A$ ) and GFAP (an astrocyte marker) (Fig. $1 B$, arrows). The staining of human brain tissue sections showed the typical structure of the human BBB, a continuous layer of EC in close contact with astrocyte end feet extended from neighboring astrocytes (Fig. $1 A-C$, arrows). To examine this interaction, our laboratory developed an in vitro model of the human BBB (Hurwitz et al., 1993; Weiss et al., 1998; Eugenin and Berman, 2003) that resembles the in vivo features of the human BBB (Fig. $1 D, E$ ), including the interaction of astrocyte end feet with the endothelial layer. This model is composed of human BMVECs, denatured collagen (representing the basement membrane), and human astrocytes cocultured on opposite sides of a filter with $3 \mu \mathrm{m}$ pores that enable end feet of astrocytes to interact with the opposite endothelial side of the filter (Fig. $1 D)$. Cross sections of this BBB model stained with vWF and GFAP demonstrate that GFAP-positive astrocyte processes establish contact with the monolayer of vWF-positive endothelial cells (Fig. $1 F-H$, arrows) in a similar way as is seen in vivo (compare with Fig. $1 A-C$ ). After $3 \mathrm{~d}$ in coculture of BMVECs and astrocytes, astrocytes send processes (astrocyte end feet) through the filter pores as shown in Figure 1, to establish contact with collagen and the endothelial layer, a typical feature of the human BBB (Eugenin and Berman, 2003). This interaction results in increased barrier differentiation and impermeability, as measured by impermeability to albumin conjugated to Evans blue dye.

HIV-infected astrocytes induce disruption of the BBB by a mechanism that is dependent on functional gap junction channels

$\mathrm{BBB}$ disruption is one of the characteristic alterations described during the pathogenesis of neuroAIDS (Dallasta et al., 1999; Luabeya et al., 2000; Eugenin et al., 2006). Thus, to examine whether HIV infection of human astrocytes alters the formation and stability of the BBB, we used uninfected or HIV-infected primary human astrocyte cultures to establish our BBB model described above. Our previous data indicated that only a few HIV-infected astrocytes $(\sim 5 \%)$ within a culture with almost undetectable viral production can spread toxicity and cellular dysregulation to neighboring uninfected astrocytes by a gap junction-dependent mechanism (Eugenin and Berman, 2007). We propose that these toxic signals generated in few HIV-infected astrocytes will alter astrocyte signaling compromising BBB integrity.

The use of uninfected human astrocytes to establish the BBB model resulted in impermeability to albumin conjugated to Evans blue dye (Fig. $2 \mathrm{~A}$, uninfected astrocytes), and no detectable endothelial apoptosis was detected by TUNEL staining (Fig. $2 B$, uninfected astrocytes). When astrocyte cultures that were HIV infected for $24 \mathrm{~h}$ were used to establish the barrier, high permeability (Fig. $2 \mathrm{~A}$, HIV-infected astrocytes) and endothelial apoptosis were detected (Fig. $2 B$, HIV-infected astrocytes), despite the fact that only $\sim 5 \%$ of the cells were infected using HIV-p24 immunofluorescence and undetectable viral replication was observed. To demonstrate that this effect was not due to any effect of cell-free virus, $2-200 \mathrm{pg} / \mathrm{ml}$ virus were added to the top or the bottom of the model. This is the amount of virus that was detected in astrocyte culture medium at $7-14 \mathrm{~d}$ after infection 

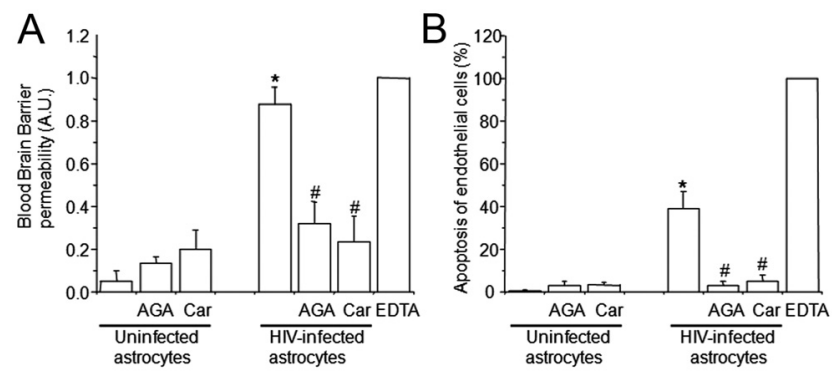

Figure 2. The use of HIV-infected astrocyte cultures to establish the human BBB model results in BBB permeability $(\boldsymbol{A})$ and endothelial apoptosis $(\boldsymbol{B})$. BBB disruption was evaluated by the permeability of the model to albumin conjugated to Evans blue dye, and endothelial apoptosis was evaluated by TUNEL. A, BBB models using uninfected astrocytes were totally impermeable to albumin conjugated to Evans blue dye. Gap junction blockers AGA or Car did not alter $B B B$ integrity when uninfected astrocytes cultures were used to establish the model. The BBB established using HIV $_{A D A}$-infected astrocyte cultures had disrupted integrity, despite no detectable infection of astrocyte cultures as assayed by p24 ELISA. Addition of gap junction blockers AGA $(32 \mu \mathrm{M})$ or $\mathrm{Car}(10 \mu \mathrm{M})$ in the bottom chamber on the BBB model (astrocyte side) inhibited BBB disruption. EDTA added to the BBB model was used as a positive control for disruption $(n=$ $4 ;{ }^{*} p \leq 0.005$ compared with control conditions using uninfected astrocytes; ${ }^{\#} p \leq 0.005$ compared with the BBB model using HIV-infected astrocytes). $\boldsymbol{B}$, Determination of endothelial apoptosis using TUNEL staining and confocal microscopy of control BBB cultures indicated no apoptosis. Gap junction blockers AGA or Car, used in treating control BBB cultures established with uninfected astrocytes, did not cause endothelial apoptosis. BBB models with $\mathrm{HIV}_{\mathrm{ADA}^{-}}$ infected astrocyte cultures exhibit significantly increased endothelial apoptosis. Addition of $\mathrm{GJ}$ blockers AGA or Car (10 $\mu \mathrm{m})$ in the bottom chamber of the BBB model (astrocyte side) totally abolished endothelial apoptosis induced by few HIV-infected astrocytes $\left(n=4\right.$; ${ }^{*} p \leq 0.005$ compared with control conditions; $" p \leq 0.005$ compared with BBB using HIV-infected astrocytes).

(Eugenin and Berman, 2007). Additionally, as a control for soluble factors, we added supernatants of uninfected or HIV-infected astrocyte cultures. No changes in BBB permeability were detected (data not illustrated). Thus, soluble factors released by HIVinfected astrocyte cultures are not inducing BBB disruption. In addition, we previously demonstrated that HIV-infected astrocytes do not release TNF- $\alpha$, IL- $1 \beta$, or IL-6 (Eugenin and Berman, 2007). Thus, these soluble factors are also not involved in BBB disruption. These data suggest that few infected astrocytes within $\mathrm{BBB}$ cocultures are inducing cellular activation and/or dysregulation resulting in BBB disruption.

We previously demonstrated that GJ channels play a key role in amplifying toxicity from $\mathrm{HIV}$-infected astrocytes to surrounding uninfected cells (Eugenin and Berman, 2007). Thus, we hypothesized that these few $\mathrm{HIV}$-infected astrocytes in the BBB model spread toxic signals to uninfected neighboring astrocytes altering signaling of astrocyte end feet by a GJ-dependent mechanism resulting in BBB disruption. To address this, we blocked GJ using two GJ blockers, 18 - $\alpha$-glycyrrhetinic acid (AGA) (32 $\mu \mathrm{M})$ or carbenoxolone (Car) $(10 \mu \mathrm{M})$. In cocultures established with HIV-infected astrocytes, the addition of the blockers each day (days 2 and 3 ) to the bottom chamber (astrocyte side) prevented the disruption of the BBB (Fig. 2A) and endothelial apoptosis (Fig. $2 B$ ) induced by HIV-infected astrocyte cultures. EDTA was used as a control for maximal BBB disruption (Fig. 2). The addition of AGA or Car alone to the bottom of the BBB model for $24 \mathrm{~h}$ after seeding of the astrocytes resulted in no significant changes in permeability (Fig. 2A) or endothelial apoptosis (Fig. $2 B$ ) when uninfected astrocytes were used to form the BBB. Thus, both BBB disruption and endothelial apoptosis triggered by few HIVinfected astrocytes were dependent on GJ channels (Fig. 2A, B).
Astrocyte end feet are dysregulated by HIV infection of astrocytes, resulting in $\mathrm{BBB}$ disruption

Blood-brain barrier integrity is disrupted during the pathogenesis of neuroAIDS by mechanisms that include increased transmigration of HIV-infected monocytes, reduction in BBB tight junction protein expression, and apoptosis (Dallasta et al., 1999; Eugenin et al., 2006). However, the exact signaling pathways that result in BBB disruption are not well understood. It has been described in other CNS diseases that alterations in physiological $\mathrm{BBB}$ signaling, especially in astrocytes, are one mechanism of BBB compromise (Simard and Nedergaard, 2004; Hawkins and Davis, 2005; Sofroniew and Vinters, 2010). Astrocyte end feet are a key component of $\mathrm{BBB}$ signaling by transducing neuronal activity to the $\mathrm{BBB}$ to regulate the dilatory response of blood vessels to increased or decreased local blood flow, which helps support changes in neuronal activity (Simard et al., 2003; Zonta et al., 2003; Filosa et al., 2006; Takano et al., 2006; Iadecola and Nedergaard, 2007; Gordon et al., 2008; Girouard et al., 2010). We propose that, during neuroAIDS pathogenesis, especially in areas in which HIV-infected astrocytes are present, the normal mechanisms that regulate vascular tone are altered, contributing to BBB disruption. To determine whether astrocytic end feet processes in contact with BMVECs are altered in BBB cocultures established with HIV-infected astrocytes compared with cocultures with uninfected cells, we evaluated the formation of these astrocyte end feet processes by confocal microscopy of the endothelial side of the BBB model.

Normally, uninfected astrocyte end feet processes are represented in the BMVEC layer of the BBB model as small GFAPpositive spots, corresponding to the astrocytic end feet in contact with the endothelium (Fig. 3, Uninfected Astr.). The use of HIVinfected cultures of astrocytes to form the BBB model resulted in misguided astrocyte end processes and aberrant interaction with the endothelium (Fig. 3, HIV-infected Astr.), as well as disruption of the monolayer of endothelial cells observed by discontinuous vWF staining (Fig. 3, HIV-infected Astr.). These alterations in astrocyte end feet processes and $\mathrm{BBB}$ disruption were reduced by the addition of the GJ blockers, Car $(10 \mu \mathrm{M})$ or AGA $(32 \mu \mathrm{M})$ (data not shown). Addition of the blockers alone to the BBB model containing uninfected astrocytes did not affect astrocyte end feet processes (data not shown). Thus, the physiological interaction between astrocyte end feet and endothelial cells was altered by HIV infection of a few astrocytes by a mechanism that involves GJ channels.

\section{HIV infection of astrocytes dysregulates astrocyte end feet signaling, resulting in $\mathrm{BBB}$ disruption}

In vivo astrocyte end feet do not have direct contact with the BMVECs due to the presence of the basement membrane. Thus, we postulated that soluble systems of communication at the end feet of the astrocytes are required to amplify toxicity from few infected astrocytes in the bottom of the insert into the endothelial layer in the top of the inserts. To examine the mechanisms by which few HIV-infected astrocytes without active viral replication alter BBB integrity, we analyzed key signaling pathways concentrated in astrocyte end feet, normally involved in vascular tone regulation. This was done by measuring BBB permeability to albumin conjugated to Evans blue dye in our BBB model established with cultures of astrocytes containing uninfected cells or cultures containing $\sim 5 \%$ infected cells. In physiological conditions, activation of cyclooxygenase (COX) and lipoxygenase (Benarroch, 2005; Yakubu and Leffler, 2005), high-conductance $\mathrm{Ca}^{2+}$-activated $\mathrm{K}^{+}\left(\mathrm{BK}_{\mathrm{Ca}}\right)$ channels (Girouard et al., 2010), and ATP receptors 

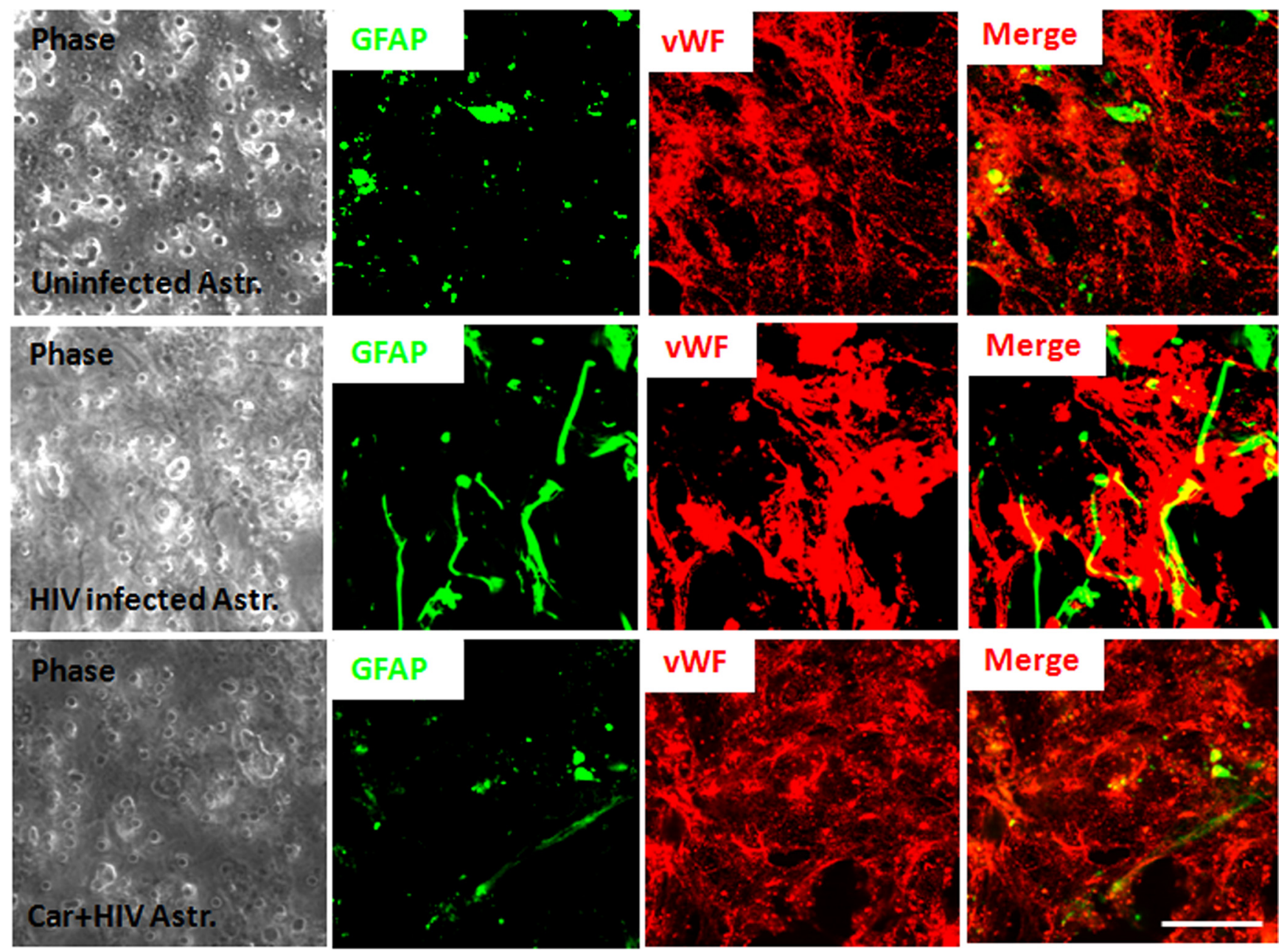

Figure 3. Astrocyte end feet are dysregulated in the presence of HIV-infected astrocytes resulting in BBB disruption and permeability. Confocal microscopy was performed on the endothelial layer (vWF and EC marker; red staining) to observe the astrocyte end feet (GFAP, an astrocyte marker; green staining) in contact with the monolayer of endothelial cells. In control conditions, localized spots of astrocyte end feet were detected in contact with the monolayer of BMVECS. The use of HIV-infected astrocyte cultures in the BBB model resulted in random localization and aberrant formation of astrocyte end feet in contact with a disrupted BMVEC. The addition of the $\mathrm{GJ}$ blocker, carbenoxolone (10 $\mu \mathrm{M})$, to the bottom of the inserts (astrocyte side), resulted in mostly normal appearing astrocyte end feet processes in contact with the monolayer of BMVECs and protection against disruption of the BMVEC monolayer $(n=3)$. Phase of the inserts shows the pores of the filters. Scale bar, $20 \mu \mathrm{m}$.

(Marrelli et al., 1999; Harrington et al., 2007; Iadecola and Nedergaard, 2007) are important signaling pathways to control CNS vascular tone and blood supply. Thus, we examined these factors.

In $\mathrm{BBB}$ models containing uninfected cultures of astrocytes, the addition to the bottom of the BBB model (astrocyte side) of AA $(1$ or $10 \mu \mathrm{M})$ or ATP $(1$ or $10 \mu \mathrm{M})$, an active product that is metabolized by lipoxygenases, $\mathrm{COX}$, and $\mathrm{P} 450$ monooxygenases and the endogenous ligand for ATP receptors, respectively, induced significant $\mathrm{BBB}$ disruption $\left({ }^{*} p=0.005\right)$ that was totally abolished by pretreatment with the GJ blocker, Car (Fig. 4A, + Car $)(10 \mu \mathrm{M})\left({ }^{*} p \leq 0.03\right)$ or AGA $(32 \mu \mathrm{M}$; + AGA) (data not shown) compared with untreated barriers (Fig. $4 A$, first bar). The inhibition of 5- and 12-lipoxygeneases, $\mathrm{COX}, \mathrm{BK}_{\mathrm{Ca}}$ channels, and purinergic receptors using baicalein (Bai), indomethacin (Indo), paxilline (Pax), or oxidized ATP (oATP), did not alter the impermeability of the barrier under control conditions (Fig. 4A, BBB established with human uninfected astrocytes). In addition, treatment with AA diluent (Dil) (Tocrisolve) or Car (10 $\mu \mathrm{M})$ alone did not alter $\mathrm{BBB}$ integrity when uninfected astrocytes were used to established the cultures (Fig. 4A). As described above, the presence of HIV-infected astrocytes in the human BBB model resulted in disruption, despite low numbers of cells being infected and undetectable viral replication. This $\mathrm{BBB}$ disruption was not further increased by treatment with AA or ATP (Fig. $4 B$ ), two treatments that induced $\mathrm{BBB}$ disruption when uninfected cocultures were used (Fig. 4A). The addition of AA diluent alone did not change the already disrupted BBB integrity when HIVinfected astrocyte cultures were used to establish the model (Fig. $4 B)$. Car treatment $(10 \mu \mathrm{M})$ alone was protective again BBB disruption when HIV-infected astrocytes were used to establish the model (Fig. 4B). Blocking 5- and 12-lipoxygeneases, $\mathrm{COX}, \mathrm{BK}_{\mathrm{Ca}}$ channels, and purinergic receptors using baicalein $(5 \mu \mathrm{M})$, indomethacin $(10 \mu \mathrm{M})$, paxilline $(1 \mu \mathrm{M})$, or oATP $(10 \mu \mathrm{M})$, respectively, resulted in significant protection against BBB disruption in cocultures with HIV-infected astrocytes $\left({ }^{\#} p<0.003\right)$. Nitric oxide signaling did not participate in the BBB disruption induced by HIV-infected astrocytes, as using donors of NO or blocking NO production with L-NAME did not alter BBB integrity (data not shown).

In BBB models containing HIV-infected cultures of astrocytes, BBB disruption induced by HIV infection of astrocytes and/or addition of AA or ATP is also astrocyte GJ dependent, because addition of carbenoxolone (10 $\mu \mathrm{M})$ (Fig. $4 A, B$, +Car) or AGA $(32 \mu \mathrm{M})$ (data not shown) to the bottom of the model 

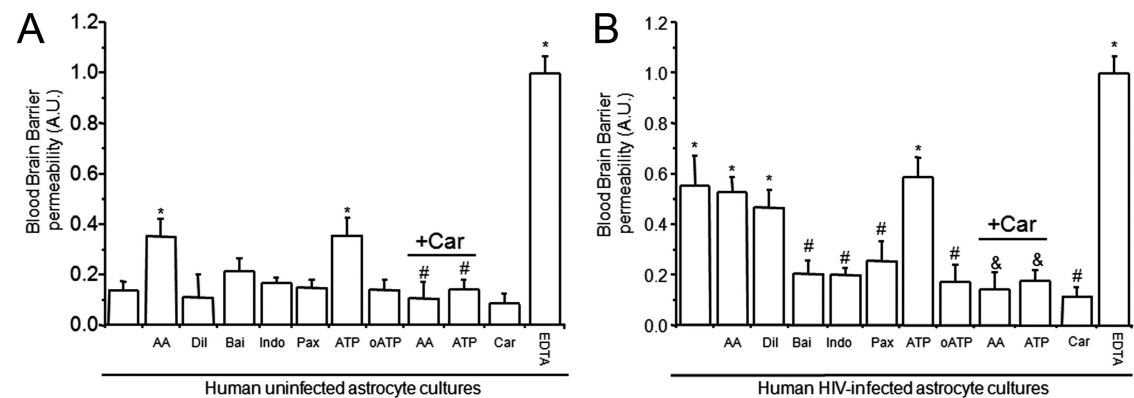

Figure 4. Astrocyte end feet signaling participate in BBB disruption mediated by few HIV-infected astrocytes. We examined whether normal signaling pathways concentrated in astrocyte end feet that regulate blood flow are altered by HIV $_{\text {ADA }}$ infection of astrocytes. We determined whether activation or blocking pathways used to control blood flow in the brain altered BBB integrity of our tissue culture model using albumin conjugated to Evans blue dye to assay for permeability. $A, B B B$ cultures established with BMVECs and uninfected human astrocytes were totally impermeable. The addition of AA or ATP to the bottom of the BBB cultures established using uninfected astrocytes induced partial BBB disruption. Blocking activation of lipoxygenase and cyclooxygenase with baicalein (Bai) and indomethacin (Indo) on the astrocyte side did not alter BBB permeability when uninfected astrocytes were using. Blocking conductance calcium-activated potassium channels $\left(\mathrm{BK}_{\mathrm{C}_{\mathrm{a}}}\right)$ with paxilline (Pax) in the bottom of the BBB model, astrocyte side, did not alter permeability. Blocking ATP purinergic receptors using oxidized ATP (oATP) did not alter permeability of the barrier when uninfected astrocytes were used for the barrier. The disruption of the BBB induced by AA and ATP was GJ dependent because carbenoxolone ( + Car) abolished disruption $\left(n=4 ;{ }^{*} p \leq 0.005\right.$ compared with control and ${ }^{\#} p \leq 0.003$ compared with BBB inserts treated with AA or ATP). $B, B B B$ cultures established using BMVECs and HIV-infected human astrocytes were highly permeable. The addition of AA, the diluent of AA (Tocrisolve), or ATP to the bottom of the BBB cultures did not change the already disrupted BBB. Blocking activation of lipoxygenase and cyclooxygenase using Bai and Indo on the astrocyte side was protective against $\mathrm{BBB}$ disruption induced by few infected astrocytes. Blocking $\mathrm{BK}_{\mathrm{Ca}}$ with Pax in the bottom of the BBB model was also protective. Blocking ATP purinergic receptors using oATP $(10 \mu \mathrm{m})$ was protective. This suggests the involvement of several signaling pathways in the BBB disruption induced by few HIV-infected astrocytes. The addition of carbenoxolone ( + Car) to the bottom of the BBB cultures abolished BBB disruption induced by AA, ATP, or HIV-infected astrocytes (as shown in Fig. 2), indicating that gap junction channels play a key role in amplifying astrocyte end feet dysregulation resulting in BMVEC compromise and permeability $\left(n=4 ;{ }^{*} p<0.005\right.$ compared with control uninfected conditions; ${ }^{\#} p<0.003$ compared with permeable BBB cultures established using HIV-infected astrocyte cultures; ${ }^{\circledR} p<0.005$ compared with treatment of BBB cultures containing HIV-infected astrocytes, treated with AA or ATP).

(astrocyte side) was protective. Thus, the mechanisms of BBB disruption induced by HIV infection of astrocytes also involve dysregulation of key signaling pathways normally concentrated in astrocyte end feet and used to control vascular tone.

\section{CNS cells in contact with SIV-infected astrocytes are apoptotic during the dynamic development of neuroAIDS}

We examined SIV-infected astrocytes in vivo to determine whether SIV-infected astrocytes are in contact with apoptotic cells during the dynamic progression of neuroAIDS as demonstration that this toxic process occurs in vivo. To address these questions, we used a model of neuroAIDS, pigtail macaques infected with SIV. In this model, $>90 \%$ of the animals develop SIV encephalitis within 3 months after inoculation with the virus (Clements et al., 2008). We analyzed brain tissue sections from three uninfected and three SIV-infected macaques at each time point after inoculation, $4,7,21,56$, and $84 \mathrm{~d}$ after inoculation, to examine infected astrocytes and bystander killing. These sections were stained for DAPI (nuclei staining), GFAP (an astrocyte marker), SIV-p41 (a viral protein), and TUNEL (an indicator of cellular apoptosis), and analyzed by confocal microscopy with subsequent three-dimensional reconstruction. The quantification of SIV-infected astrocytes was performed using colocalization of SIV-p41 and GFAP staining resulting in $8.2 \pm 3.9 \%$ of the total GFAP-positive cells being infected in brain sections at 21 or $56 \mathrm{~d}$ after inoculation as quantified using an imaging software, NIS advance research (Nikon). Uninfected sections did not show any SIV-p41 staining (Fig. 5, row 1). In SIV-infected sections, we observed that SIV-infected astrocytes (Fig. 5, row 2, arrows), as in our in vitro model, were also in close contact with apoptotic brain endothelial cells (Fig. 5, row 2, arrowheads) (56 d after infection close to the $\mathrm{BBB})$. In the parenchyma, we also observed clusters of SIV-infected astrocytes in contact with uninfected neighboring apoptotic cells (Fig. 5, row 3, arrowheads) (56 d after infection in the parenchymal cells). This pattern of cellular apoptosis was associated with the presence of a small percentage of SIV-infected astrocytes and was most evident at days 21 and $56 \mathrm{~d}$ after inoculation and correlated with the severity of the disease. No significant levels of apoptosis were detected in brain areas without infection of astrocytes (data not shown). We did not quantify apoptosis in the brain sections from $84 \mathrm{~d}$ after inoculation because inflammatory responses and tissue damage made it difficult to identify clearly SIV-infected astrocytes as well as the organization of the CNS parenchyma. As we described previously in vitro, HIVinfected cells are protected from apoptosis; however, uninfected cells surrounding clusters of infection undergo apoptosis (Eugenin and Berman, 2007). We now demonstrate in vivo that SIV-infected clusters of astrocytes close to blood vessels or in the parenchyma are not apoptotic during the time points examined. Thus, SIV-infected astrocytes in vivo also appear to be protected from apoptosis. In addition, we stained brain sections obtained from uninfected and SIV infected $(4-84 \mathrm{~d})$ for CD68 or isolectin-B4 (to identify cells of the monocyte/macrophage lineage), SIV-p41, and TUNEL, and no correlation between CD68 staining and cell-to-cell apoptosis was detected (data not shown), despite the fact that CD68 staining increased during the time course of the disease (mild disease) by $145 \pm 56 \%$, indicating activation compared with that found in uninfected animals between 4 and $56 \mathrm{~d}$ after infection. At later time points, $84 \mathrm{~d}$ after infection, when there is most often severe encephalitic disease, it was not possible to establish a clear correlation between cell communication and apoptosis due to tissue disorganization and excessive inflammation. This increase in CD68 intensity correlated with an increase in the percentage of SIV-infected CD68-positive cells from $0 \%$ (in uninfected macaques) to $31 \pm 29 \%$ from 7 to $84 \mathrm{~d}$ after infection depending on the degree of encephalitis. However, despite the increase in percentage of SIV-infected cells, no correlation was found with cell-to-cell apoptosis. However, we cannot rule out their participation in inflammation. Thus, our data underscore that HIV infection of a small percentage of astrocytes, astrocyte dysregulation, and cell-to-cell contact are extremely important for cell death.

\section{Discussion}

In this report, we demonstrate that HIV infection of astrocyte cultures, despite low numbers of infected cells $(4.7 \pm 2.8 \%$ in vitro and $8.2 \pm 3.9 \%$ in vivo using an SIV model) and undetectable viral replication, when used to establish a culture model of the human BBB, results in BBB disruption by a mechanism that involves EC apoptosis and alterations in astrocyte end feet formation and signaling. All of these effects are mediated by func- 

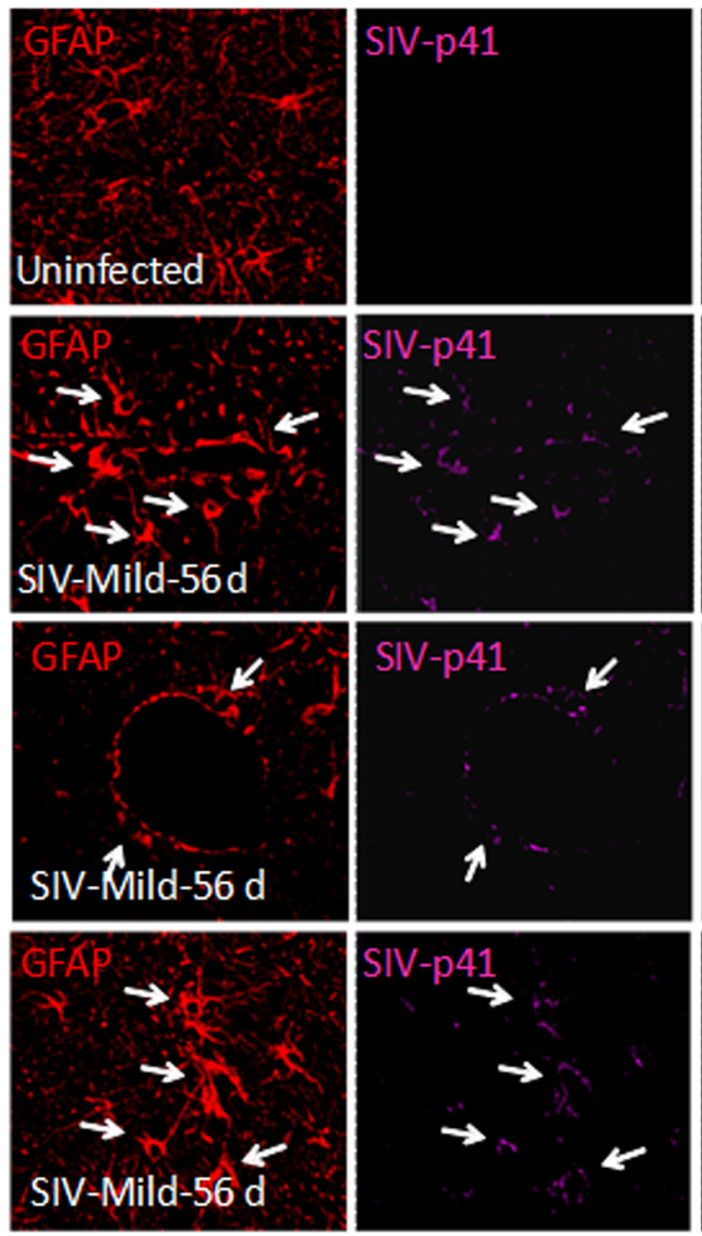
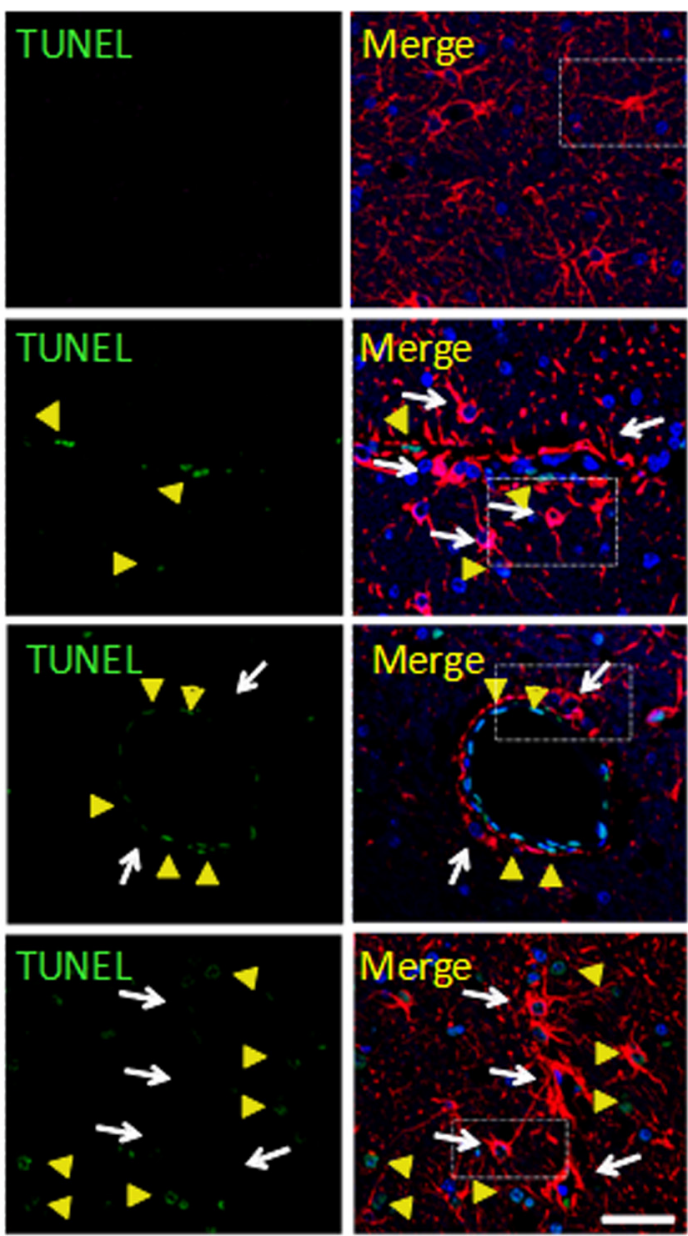
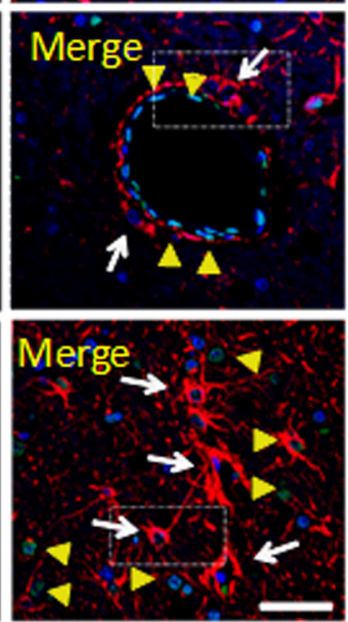
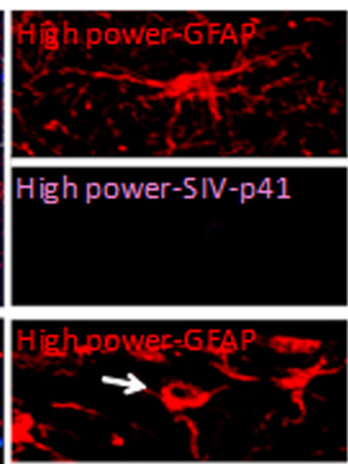

High power-5IV-p41 $\rightarrow$
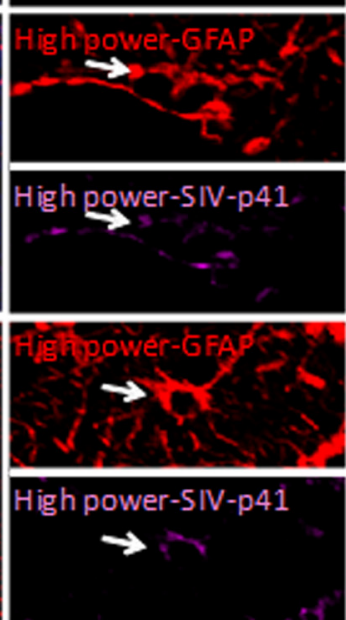

Figure 5. SIV-infected astrocytes are detected in vivo $(8.2 \pm 3.9 \%)$ and are found in close proximity to apoptotic neighboring cells. SIV-infected astrocytes are not apoptotic. Confocal analyses and subsequent three-dimensional reconstructions were performed using tissue sections obtained from uninfected and mildly encephalitic macaques $21-84 \mathrm{~d}$ after SIV infection. Tissue was stained for nuclei (DAPI; blue), GFAP (astrocyte marker; red), TUNEL (apoptosis; green), and SIV-p41 (SIV; magenta). Uninfected tissue sections showed uniform astrocyte staining with extensive processes and no apoptosis and no staining for SIV-p41 protein. Staining of brain tissue sections obtained from 21 and $56 \mathrm{~d}$ after infection showed $8.2 \pm 3.9 \%$ infected astrocytes. Animals with mild encephalitis at $56 \mathrm{~d}$ after infection had significant infection of astrocytes (white arrows) and apoptosis in neighboring uninfected endothelial cells (yellow arrows, second row) and astrocytes (yellow arrows, third row). SIV-infected astrocytes did not apoptose. The white box in the merge pictures represents the area amplified in the last column to demonstrate colocalization of GFAP and SIV-p41 staining (arrows indicated SIV-infected astrocytes). In severe encephalitis (data not shown) due to the significant loss of parenchymal organization and extensive inflammation, it was not possible to assay reliably for SIV infection of astrocytes or apoptosis in neighboring cells. Scale bar, $40 \mu \mathrm{m}$.

tional GJ channels, because blocking these channels reduced the $\mathrm{BBB}$ disruption triggered by few infected astrocytes.

In vivo, microglial cells and perivascular macrophages are the predominant cell types productively infected by HIV-1 (Wiley et al., 1986). However, HIV infection of astrocytes has also been reported in vivo and in vitro, characterized by low viral replication and few infected cells (Tontsch and Bauer, 1991; Conant et al., 1994; Saito et al., 1994; Tornatore et al., 1994a,b; Ranki et al., 1995; Ohagen et al., 1999; Eugenin and Berman, 2007). HIV-1 mRNA and DNA have been detected in astrocytes within the adult and pediatric brains of individuals with AIDS (Wiley et al., 1986, 1991; Tornatore et al., 1994b), representing 1-3\% of the total astrocytes (Nuovo et al., 1994; Bagasra et al., 1996; Takahashi et al., 1996). Recently, with improved techniques, HIV DNA has been detected in up to $19 \%$ of astrocytes in human brain sections (Churchill et al., 2009), suggesting that HIV-infected cells are active participants in the dysregulation of the CNS observed in HIV-infected individuals and serve as an important viral reservoir within the CNS. Our data using primary cultures of human astrocytes demonstrated that $4.7 \pm 2.8 \%$ of the cells are infected after virus exposure and using an animal model of accel- erated neuroAIDS, SIV-infected macaques, we demonstrated that at least $8.2 \pm 3.9 \%$ of the astrocyte population are SIV infected during the time course of the disease (21-56 d after infection in the mild and severe encephalitic animals).

Our previous data indicated that HIV infection of human astrocytes resulted in bystander killing of uninfected neighboring astrocytes (Eugenin and Berman, 2007) and neurons (E. A. Eugenin and J. W. Berman, unpublished data) by a mechanism that involves functional gap junction channels to spread toxic signals (Eugenin and Berman, 2007). In vivo, at the BBB, astrocytes almost completely cover the endothelial cells with their end foot processes separated by a basement membrane (Kacem et al., 1998). Our understanding of the communication systems between astrocytes and BMVECs is increasing, especially the contribution of astrocyte end feet to BBB physiology (Abbott, 2002; Simard et al., 2003; Iadecola and Nedergaard, 2007; Girouard et al., 2010). The potential effects of other cell types at the BBB, such as pericytes, smooth muscle cells, and perivascular macrophages that also participate in regulating BBB function in normal and pathological conditions, should be considered in future experiments (Rubin and Staddon, 1999). In this study, we addressed 
some of the basic mechanisms by which HIV infection of even small numbers of astrocytes alters BBB integrity and function.

Endothelial apoptosis in neuroAIDS has been detected (Shi et al., 1996; Ullrich et al., 2000; Huang et al., 2001; Acheampong et al., 2005; Yano et al., 2007); however, the mechanisms that contribute to this toxicity are not well understood. We demonstrated that endothelial compromise induced by few infected astrocytes is dependent on functional astrocytic gap junctions because blocking these channels resulted in BBB protection. Using uninfected or HIV-infected astrocyte cultures to establish the human BBB model, we demonstrated that only a few HIV-infected astrocytes are sufficient to cause a profound effect on $\mathrm{BBB}$ integrity and endothelial apoptosis. The BBB disruption induced by few HIV-infected astrocytes in these cultures altered the guidance and functions of astrocyte end feet close to BMVECs and was also gap junction dependent. Astrocytic end feet have specialized features that contribute to the regulation of water homeostasis, calcium signaling, and regulation of blood flow, suggesting that these structures play a key role in communicating or amplifying astrocytic signals into BMVECs, despite the presence of the basement membrane (Kim et al., 2006). We identified particular signaling pathways, mainly concentrated in astrocyte end feet that contribute to $\mathrm{BBB}$ disruption. Under normal conditions, these pathways participate in control of vascular tone by an equilibrated production of both dilatory and constrictor agents (Paemeleire and Leybaert, 2000; Abbott, 2002; Simard et al., 2003; Zonta et al., 2003; Bogatcheva et al., 2005; Yakubu and Leffler, 2005; Kim et al., 2006; Iadecola and Nedergaard, 2007; Girouard et al., 2008). Using our BBB model, we showed that activation or blocking the activation of pathways required for control of blood flow, in the astrocyte side of the model, resulted in no significant changes in $\mathrm{BBB}$ permeability when inhibition of lipoxygenase, $\mathrm{COX}$, high-conductance $\mathrm{Ca}^{2+}$-activated $\mathrm{K}^{+}\left(\mathrm{BK}_{\mathrm{Ca}}\right)$ channels, and purinergic ATP receptors, in cocultures with uninfected astrocytes did not alter BBB permeability. Addition of AA or ATP to the astrocyte layer resulted in BBB disruption. Blocking these individual signaling pathways in cocultures with HIV-infected astrocytes resulted in protection against BBB disruption, suggesting that multiple signaling pathways contribute to the disruption induced by few infected astrocytes. In agreement with our previous data, GJ blockers, AGA or Car, completely abolished BBB disruption induced by HIV-infected cultures of astrocytes as well as by direct application of COX activation subproduct, AA, or direct activation of ATP receptors, ATP, to the BBB using uninfected astrocytes, suggesting that gap junctional signaling is required for amplification of BBB dysfunction in the context of HIV infection and inflammation in the CNS. During the pathogenesis of many CNS diseases, dysregulation of these signaling pathways has been described, but they had not been examined in the context of BBB disruption and/or HIV infection. Increased arachidonic acid release, adenosine/ATP, prostaglandins, increased $\mathrm{K}^{+}$, and activation of $\mathrm{BK}_{\mathrm{Ca}}$ channels have been demonstrated to participate in control of blood flow within the CNS (Benarroch, 2005; Bogatcheva et al., 2005; Yakubu and Leffler, 2005; Kim et al., 2006; Girouard et al., 2010). All these changes in signaling are triggered by excessive neuronal signaling, such as excitotoxicity, energy failure, ischemia, and neurodegeneration, all features characteristic of neuroAIDS. Thus, we propose that toxic signals generated in few HIV-infected astrocytes are spread by GJ to neighboring cells, and additionally to the astrocyte end feet, resulting in aberrant glial-vascular signaling resulting in $\mathrm{BBB}$ dysregulation and disruption. In addition to the bystander killing mediated by GJ, we cannot rule out the participation of $\mathrm{Cx}$ hemichannels, especially at the end feet of the astrocytes, because GJ blockers also block these hemichannels (Spray et al., 2006; Giaume and Theis, 2010; Hamilton and Attwell, 2010). Thus, as techniques to block specifically GJ or hemichannels become available, these questions can be addressed.

To demonstrate the presence of infected astrocytes in vivo and the potential contribution of these infected cells to the amplification of toxicity to neighboring cells, we used an animal model of accelerated neuroAIDS, SIV-infected macaques. Using this model, we detected significant numbers of SIV-infected astrocytes, $8.2 \pm 3.9 \%$, in close interaction with the endothelium as well as in the CNS parenchyma. These numbers are in agreement with those described for HIV-infected astrocytes in vivo and in vitro (Wiley et al., 1986, 1991; Tontsch and Bauer, 1991; Conant et al., 1994; Nuovo et al., 1994; Saito et al., 1994; Tornatore et al., 1994a,b; Ranki et al., 1995; Bagasra et al., 1996; Takahashi et al., 1996; Ohagen et al., 1999; Eugenin and Berman, 2007; Churchill et al., 2009). In addition, as in our in vitro experiments (Eugenin and Berman, 2007), we detected that SIV-infected astrocytes are not susceptible to apoptosis but that uninfected cells surrounding these clusters of infected cells apoptose extensively. Thus, our data in vivo indicate that, despite minimal SIV infection of astrocytes, significant changes in BBB integrity and apoptosis in parenchymal cells are observed. Our compelling data in vivo are strongly supported by our in vitro data that cell-to-cell killing is GJ dependent between HIV-infected and uninfected astrocytes.

We demonstrated that a few HIV-infected astrocytes trigger bystander cellular dysfunction and endothelial apoptosis, resulting in BBB compromise. Thus, despite the low number of HIVinfected astrocytes, considerable damage can be spread to uninfected cells by a gap junction-dependent mechanism. Our data suggest that astrocytes participate actively in the CNS dysfunction observed in HIV-infected individuals and that gap junction channels amplify toxicity and dysfunctional signaling to other areas of the brain. These data represent a novel mechanism in neuroAIDS and indicate potential new targets for therapeutic interventions to reduce the ongoing CNS effects of HIV and to eradicate CNS viral reservoirs.

\section{References}

Abbott NJ (2002) Astrocyte-endothelial interactions and blood-brain barrier permeability. J Anat 200:629-638.

Acheampong EA, Parveen Z, Muthoga LW, Kalayeh M, Mukhtar M, Pomerantz RJ (2005) Human immunodeficiency virus type 1 Nef potently induces apoptosis in primary human brain microvascular endothelial cells via the activation of caspases. J Virol 79:4257-4269.

Anthony IC, Ramage SN, Carnie FW, Simmonds P, Bell JE (2005) Influence of HAART on HIV-related CNS disease and neuroinflammation. J Neuropathol Exp Neurol 64:529-536.

Babas T, Vieler E, Hauer DA, Adams RJ, Tarwater PM, Fox K, Clements JE, Zink MC (2001) Pathogenesis of SIV pneumonia: selective replication of viral genotypes in the lung. Virology 287:371-381.

Bagasra O, Lavi E, Bobroski L, Khalili K, Pestaner JP, Tawadros R, Pomerantz RJ (1996) Cellular reservoirs of HIV-1 in the central nervous system of infected individuals: identification by the combination of in situ polymerase chain reaction and immunohistochemistry. AIDS 10:573-585.

Ballabh P, Braun A, Nedergaard M (2004) The blood-brain barrier: an overview: structure, regulation, and clinical implications. Neurobiol Dis 16:1-13.

Benarroch EE (2005) Neuron-astrocyte interactions: partnership for normal function and disease in the central nervous system. Mayo Clin Proc $80: 1326-1338$.

Bogatcheva NV, Sergeeva MG, Dudek SM, Verin AD (2005) Arachidonic acid cascade in endothelial pathobiology. Microvasc Res 69:107-127.

Churchill MJ, Wesselingh SL, Cowley D, Pardo CA, McArthur JC, Brew BJ, Gorry PR (2009) Extensive astrocyte infection is prominent in human immunodeficiency virus-associated dementia. Ann Neurol 66:253-258. 
Clements JE, Mankowski JL, Gama L, Zink MC (2008) The accelerated simian immunodeficiency virus macaque model of human immunodeficiency virus-associated neurological disease: from mechanism to treatment. J Neurovirol 14:309-317.

Conant K, Tornatore C, Atwood W, Meyers K, Traub R, Major EO (1994) In vivo and in vitro infection of the astrocyte by HIV-1. Adv Neuroimmunol 4:287-289.

Cosenza MA, Zhao ML, Si Q, Lee SC (2002) Human brain parenchymal microglia express CD14 and CD45 and are productively infected by HIV-1 in HIV-1 encephalitis. Brain Pathol 12:442-455.

Dallasta LM, Pisarov LA, Esplen JE, Werley JV, Moses AV, Nelson JA, Achim CL (1999) Blood-brain barrier tight junction disruption in human immunodeficiency virus-1 encephalitis. Am J Pathol 155:1915-1927.

Danave IR, Tiffany-Castiglioni E, Zenger E, Barhoumi R, Burghardt RC, Collisson EW (1994) Feline immunodeficiency virus decreases cell-cell communication and mitochondrial membrane potential. J Virol 68:6745-6750.

Eugenin EA, Berman JW (2003) Chemokine-dependent mechanisms of leukocyte trafficking across a model of the blood-brain barrier. Methods 29:351-361.

Eugenin EA, Berman JW (2007) Gap junctions mediate human immunodeficiency virus-bystander killing in astrocytes. J Neurosci 27:12844-12850.

Eugenin EA, D’Aversa TG, Lopez L, Calderon TM, Berman JW (2003) MCP-1 (CCL2) protects human neurons and astrocytes from NMDA or HIV-tat-induced apoptosis. J Neurochem 85:1299-1311.

Eugenin EA, Osiecki K, Lopez L, Goldstein H, Calderon TM, Berman JW (2006) CCL2/monocyte chemoattractant protein-1 mediates enhanced transmigration of human immunodeficiency virus (HIV)-infected leukocytes across the blood-brain barrier: a potential mechanism of HIV-CNS invasion and neuroAIDS. J Neurosci 26:1098-1106.

Faccini AM, Cairney M, Ashrafi GH, Finbow ME, Campo MS, Pitts JD (1996) The bovine papillomavirus type $4 \mathrm{E} 8$ protein binds to ductin and causes loss of gap junctional intercellular communication in primary fibroblasts. J Virol 70:9041-9045.

Filosa JA, Bonev AD, Straub SV, Meredith AL, Wilkerson MK, Aldrich RW, Nelson MT (2006) Local potassium signaling couples neuronal activity to vasodilation in the brain. Nat Neurosci 9:1397-1403.

Flaherty MT, Hauer DA, Mankowski JL, Zink MC, Clements JE (1997) Molecular and biological characterization of a neurovirulent molecular clone of simian immunodeficiency virus. J Virol 71:5790-5798.

Fox HS, Weed MR, Huitron-Resendiz S, Baig J, Horn TF, Dailey PJ, Bischofberger N, Henriksen SJ (2000) Antiviral treatment normalizes neurophysiological but not movement abnormalities in simian immunodeficiency virus-infected monkeys. J Clin Invest 106:37-45.

Giaume C, Theis M (2010) Pharmacological and genetic approaches to study connexin-mediated channels in glial cells of the central nervous system. Brain Res Rev 63:160-176.

Girouard H, Lessard A, Capone C, Milner TA, Iadecola C (2008) The neurovascular dysfunction induced by angiotensin II in the mouse neocortex is sexually dimorphic. Am J Physiol Heart Circ Physiol 294:H156-H163.

Girouard H, Bonev AD, Hannah RM, Meredith A, Aldrich RW, Nelson MT (2010) Astrocytic endfoot $\mathrm{Ca}^{2+}$ and BK channels determine both arteriolar dilation and constriction. Proc Natl Acad Sci U S A 107:3811-3816.

Goldstein GW (1988) Endothelial cell-astrocyte interactions. A cellular model of the blood-brain barrier. Ann N Y Acad Sci 529:31-39.

Gordon GR, Choi HB, Rungta RL, Ellis-Davies GC, MacVicar BA (2008) Brain metabolism dictates the polarity of astrocyte control over arterioles. Nature 456:745-749.

Hamilton NB, Attwell D (2010) Do astrocytes really exocytose neurotransmitters? Nat Rev Neurosci 11:227-238.

Harrington LS, Evans RJ, Wray J, Norling L, Swales KE, Vial C, Ali F, Carrier MJ, Mitchell JA (2007) Purinergic 2X1 receptors mediate endothelial dependent vasodilation to ATP. Mol Pharmacol 72:1132-1136.

Hawkins BT, Davis TP (2005) The blood-brain barrier/neurovascular unit in health and disease. Pharmacol Rev 57:173-185.

Hayashi Y, Nomura M, Yamagishi S, Harada S, Yamashita J, Yamamoto H (1997) Induction of various blood-brain barrier properties in nonneural endothelial cells by close apposition to co-cultured astrocytes. Glia 19:13-26.

Huang MB, Khan M, Garcia-Barrio M, Powell M, Bond VC (2001) Apoptotic effects in primary human umbilical vein endothelial cell cultures caused by exposure to virion-associated and cell membrane-associated HIV-1 gp120. J Acquir Immune Defic Syndr 27:213-221.

Hurwitz AA, Berman JW, Rashbaum WK, Lyman WD (1993) Human fetal astrocytes induce the expression of blood-brain barrier specific proteins by autologous endothelial cells. Brain Res 625:238-243.

Hurwitz AA, Berman JW, Lyman WD (1994) The role of the blood-brain barrier in HIV infection of the central nervous system. Adv Neuroimmunol 4:249-256.

Iadecola C, Nedergaard M (2007) Glial regulation of the cerebral microvasculature. Nat Neurosci 10:1369-1376.

Kacem K, Lacombe P, Seylaz J, Bonvento G (1998) Structural organization of the perivascular astrocyte endfeet and their relationship with the endothelial glucose transporter: a confocal microscopy study. Glia 23:1-10.

Kielian T, Esen N (2004) Effects of neuroinflammation on glia-glia gap junctional intercellular communication: a perspective. Neurochem Int 45:429-436.

Kim JH, Kim JH, Park JA, Lee SW, Kim WJ, Yu YS, Kim KW (2006) Bloodneural barrier: intercellular communication at glio-vascular interface. J Biochem Mol Biol 39:339-345.

Knabb MT, Danielsen CA, McShane-Kay K, Mbuy GK, Woodruff RI (2007) Herpes simplex virus-type 2 infectivity and agents that block gap junctional intercellular communication. Virus Res 124:212-219.

Luabeya MK, Dallasta LM, Achim CL, Pauza CD, Hamilton RL (2000) Blood-brain barrier disruption in simian immunodeficiency virus encephalitis. Neuropathol Appl Neurobiol 26:454-462.

Mankowski JL, Flaherty MT, Spelman JP, Hauer DA, Didier PJ, Amedee AM, Murphey-Corb M, Kirstein LM, Muñoz A, Clements JE, Zink MC (1997) Pathogenesis of simian immunodeficiency virus encephalitis: viral determinants of neurovirulence. J Virol 71:6055-6060.

Mankowski JL, Queen SE, Clements JE, Zink MC (2004) Cerebrospinal fluid markers that predict SIV CNS disease. J Neuroimmunol 157:66-70.

Marrelli SP, Khorovets A, Johnson TD, Childres WF, Bryan RM Jr (1999) P2 purinoceptor-mediated dilations in the rat middle cerebral artery after ischemia-reperfusion. Am J Physiol 276:H33-H41.

Nuovo GJ, Gallery F, MacConnell P, Braun A (1994) In situ detection of polymerase chain reaction-amplified HIV-1 nucleic acids and tumor necrosis factor-alpha RNA in the central nervous system. Am J Pathol 144:659-666.

Ohagen A, Ghosh S, He J, Huang K, Chen Y, Yuan M, Osathanondh R, Gartner S, Shi B, Shaw G, Gabuzda D (1999) Apoptosis induced by infection of primary brain cultures with diverse human immunodeficiency virus type 1 isolates: evidence for a role of the envelope. J Virol 73:897-906

Paemeleire K, Leybaert L (2000) ATP-dependent astrocyte-endothelial calcium signaling following mechanical damage to a single astrocyte in astrocyte-endothelial co-cultures. J Neurotrauma 17:345-358.

Ranki A, Nyberg M, Ovod V, Haltia M, Elovaara I, Raininko R, Haapasalo H, Krohn K (1995) Abundant expression of HIV Nef and Rev proteins in brain astrocytes in vivo is associated with dementia. AIDS 9:1001-1008.

Risau W (1991) Induction of blood-brain barrier endothelial cell differentiation. Ann N Y Acad Sci 633:405-419.

Risau W, Wolburg H (1990) Development of the blood-brain barrier. Trends Neurosci 13:174-178.

Rouach N, Avignone E, Même W, Koulakoff A, Venance L, Blomstrand F, Giaume C (2002) Gap junctions and connexin expression in the normal and pathological central nervous system. Biol Cell 94:457-475.

Rubin LL, Staddon JM (1999) The cell biology of the blood-brain barrier. Annu Rev Neurosci 22:11-28.

Saez JC, Berthoud VM, Branes MC, Martinez AD, Beyer EC (2003) Plasma membrane channels formed by connexins: their regulation and functions. Physiol Rev 83:1359-1400.

Saito Y, Sharer LR, Epstein LG, Michaels J, Mintz M, Louder M, Golding K, Cvetkovich TA, Blumberg BM (1994) Overexpression of nef as a marker for restricted HIV-1 infection of astrocytes in postmortem pediatric central nervous tissues. Neurology 44:474-481.

Shi B, De Girolami U, He J, Wang S, Lorenzo A, Busciglio J, Gabuzda D (1996) Apoptosis induced by HIV-1 infection of the central nervous system. J Clin Invest 98:1979-1990.

Simard M, Nedergaard M (2004) The neurobiology of glia in the context of water and ion homeostasis. Neuroscience 129:877-896.

Simard M, Arcuino G, Takano T, Liu QS, Nedergaard M (2003) Signaling at the gliovascular interface. J Neurosci 23:9254-9262. 
Sofroniew MV, Vinters HV (2010) Astrocytes: biology and pathology. Acta Neuropathol 119:7-35.

Spray DC, Ye ZC, Ransom BR (2006) Functional connexin "hemichannels": a critical appraisal. Glia 54:758-773.

Takahashi K, Wesselingh SL, Griffin DE, McArthur JC, Johnson RT, Glass JD (1996) Localization of HIV-1 in human brain using polymerase chain reaction/in situ hybridization and immunocytochemistry. Ann Neurol 39:705-711.

Takano T, Tian GF, Peng W, Lou N, Libionka W, Han X, Nedergaard M (2006) Astrocyte-mediated control of cerebral blood flow. Nat Neurosci 9:260-267.

Tontsch U, Bauer HC (1991) Glial cells and neurons induce blood-brain barrier related enzymes in cultured cerebral endothelial cells. Brain Res 539:247-253.

Tornatore C, Meyers K, Atwood W, Conant K, Major E (1994a) Temporal patterns of human immunodeficiency virus type 1 transcripts in human fetal astrocytes. J Virol 68:93-102.

Tornatore C, Chandra R, Berger JR, Major EO (1994b) HIV-1 infection of subcortical astrocytes in the pediatric central nervous system. Neurology 44:481-487.

Ullrich CK, Groopman JE, Ganju RK (2000) HIV-1 gp120- and gp160induced apoptosis in cultured endothelial cells is mediated by caspases. Blood 96:1438-1442.

Weiss JM, Downie SA, Lyman WD, Berman JW (1998) Astrocyte-derived monocyte-chemoattractant protein-1 directs the transmigration of leu- kocytes across a model of the human blood-brain barrier. J Immunol 161:6896-6903.

Wiley CA, Schrier RD, Nelson JA, Lampert PW, Oldstone MB (1986) Cellular localization of human immunodeficiency virus infection within the brains of acquired immune deficiency syndrome patients. Proc Natl Acad Sci U S A 83:7089-7093.

Wiley CA, Masliah E, Morey M, Lemere C, DeTeresa R, Grafe M, Hansen L, Terry R (1991) Neocortical damage during HIV infection. Ann Neurol 29:651-657.

Yakubu MA, Leffler CW (2005) Regulation of cerebral microvascular endothelial cell cyclooxygenase- 2 message and activity by blood derived vasoactive agents. Brain Res Bull 68:150-156.

Yano M, Nakamuta S, Shiota M, Endo H, Kido H (2007) Gatekeeper role of 14-3-3tau protein in HIV-1 gp120-mediated apoptosis of human endothelial cells by inactivation of Bad. AIDS 21:911-920.

Zink MC, Suryanarayana K, Mankowski JL, Shen A, Piatak M Jr, Spelman JP, Carter DL, Adams RJ, Lifson JD, Clements JE (1999) High viral load in the cerebrospinal fluid and brain correlates with severity of simian immunodeficiency virus encephalitis. J Virol 73:10480-10488.

Zink MC, Coleman GD, Mankowski JL, Adams RJ, Tarwater PM, Fox K, Clements JE (2001) Increased macrophage chemoattractant protein-1 in cerebrospinal fluid precedes and predicts simian immunodeficiency virus encephalitis. J Infect Dis 184:1015-1021.

Zonta M, Angulo MC, Gobbo S, Rosengarten B, Hossmann KA, Pozzan T, Carmignoto G (2003) Neuron-to-astrocyte signaling is central to the dynamic control of brain microcirculation. Nat Neurosci 6:43-50. 